\title{
Rapid PCR detection of group a streptococcus from flocked throat swabs: A retrospective clinical study
}

\author{
Robert Slinger ${ }^{1 *}$, David Goldfarb², Derek Rajakumar ${ }^{1}$, loana Moldovan ${ }^{1}$, Nicholas Barrowman ${ }^{3}$, Ronald Tam ${ }^{1}$ and \\ Francis Chan ${ }^{1}$
}

\begin{abstract}
Background: Rapid diagnosis of GAS pharyngitis may improve patient care by ensuring that patients with GAS pharyngitis are treated quickly and also avoiding unnecessary use of antibiotics in those without GAS infection. Very few molecular methods for detection of GAS in clinical throat swab specimens have been described.

Methods: We performed a study of a laboratory-developed internally-controlled rapid Group A streptococcus (GAS) PCR assay using flocked swab throat specimens. We compared the GAS PCR assay to GAS culture results using a collection of archived throat swab samples obtained during a study comparing the performance of conventional and flocked throat swabs.
\end{abstract}

Results: The sensitivity of the GAS PCR assay as compared to the reference standard was $96.0 \%(95 \% \mathrm{Cl} 90.1 \%$ to 98.4\%), specificity 98.6\% (95\% Cl 95.8\% to 99.5\%), positive predictive value (PPV) 96.9\% (95\% Cl 91.4\% to 99.0\%) and negative predictive value (NPV) of $98.1 \%$ (95\% Cl $95.2 \%$ to $99.2 \%)$. For conventional swab cultures, sensitivity was $96.0 \%$ (95\% Cl $90.1 \%$ to $98.4 \%$ ), specificity $100 \%$ (95\% Cl $98.2 \%$ to $100 \%)$, PPV $100 \%$, (95\% Cl $96.1 \%$ to $100 \%$ ) and NPV $98.1 \%$ (95\% Cl 95.2\% to $99.3 \%)$

Conclusions: In this retrospective study, the GAS PCR assay appeared to perform as well as conventional throat swab culture, the current standard of practice. Since the GAS PCR assay, including DNA extraction, can be performed in approximately 1 hour, prospective studies of this assay are warranted to evaluate the clinical impact of the assay on management of patients with pharyngitis.

Keywords: PCR, rapid, internally-controlled, LCGreen, Group A Streptococcus, pharyngitis, flocked swab

\section{Background}

Rapid diagnosis of Streptococcus pyogenes, commonly referred to as group A streptococcus (GAS), from throat specimens may be useful for patient management, both ensuring that patients with GAS pharyngitis are treated quickly and also avoiding unnecessary use of antibiotics in those without GAS infection. Surprisingly, there have been very few reports of nucleic acid (NA) amplification assays for rapid GAS detection from throat swabs $[1,2]$. The lack of published reports in this area may reflect concerns about the costs and complexity of NA amplification methods relative to culture and antigen detection methods.

\footnotetext{
* Correspondence: slinger@cheo.on.ca

'Department of Laboratory Medicine, Children's Hospital of Eastern Ontario, University of Ottawa, Ottawa, ON, Canada

Full list of author information is available at the end of the article
}

We therefore designed an internally-controlled, rapid and relatively inexpensive PCR assay for GAS pharyngitis, and retrospectively evaluated this assay using archived throat swab specimens. The assay made use of recent innovations in specimen collection and nucleic acid amplification by using the new flocked swabs for specimen collection and by using a newer intercalating dye, LC Green, for amplicon detection [3,4].

\section{Methods}

PCR primers and internal amplification control design

We chose the dnase $B$ gene as our target since this gene appears to be both present in all S. pyogenes and also unique to this organism [5]. We designed a PCR primer pair to amplify a dnaseB gene sequence using the Primer3 program [6]. In order to determine if PCR inhibition was present in any specimens, we designed a competitive 
internal amplification control (IAC) oligonucleotide that would be amplified by the GAS primers selected, but have a lower melting temperature $\left(T_{\mathrm{m}}\right)$. The primers and the IAC sequences are shown in Table 1.

\section{PCR protocol}

The primers and the internal control oligonucleotide were synthesized by Integrated DNA Technologies, Inc (Coralville, ID). PCR reactions were performed in $10 \mu \mathrm{L}$ volume, including $4 \mu \mathrm{L}$ of Light Scanner master mix containing the LCGreen Plus + dye (Idaho Technology Inc., Salt Lake City, UT), a $0.5 \mu \mathrm{mol} / \mathrm{L}$ concentration of each primer, a 1 picomolar concentration of internal control oligonucleotide and $1 \mu \mathrm{L}$ of specimen DNA.

The thermocycler (RapidCycler II, Idaho Technology Inc.) protocol consisted of 40 cycles of $95^{\circ} \mathrm{C}$ denaturation, $60^{\circ} \mathrm{C}$ annealing, $72^{\circ} \mathrm{C}$ extension with a 10 second hold at each temperature and a programmed transition rate of $9.9^{\circ} \mathrm{C}$ per second, with a total run time of 35 minutes.

After PCR, samples were transferred to the high-resolution melting instrument (HR-1). A rate of $0.3^{\circ} \mathrm{C}$ per second was used when measuring the fluorescence change of the sample in a temperature range of $60^{\circ} \mathrm{C}$ to $90^{\circ} \mathrm{C}$. The derivative of the measured fluorescence plotted against temperature was displayed using the HR-1 software and the peak of these curves was measured to obtain the amplicon $T_{\mathrm{m}}$.

\section{Specificity panel}

Prior to clinical specimen testing, we verified primer specificity in silica using the BLAST tool, and in vitro against a panel of DNA extracts from a collection of reference bacterial strains. These included Streptococcus dysgalactiae subsp. equisimilis (large-colony Lancefield antigen Group $C$ and $G$ positive beta-hemolytic streptococci), S. agalactiae (Group B streptococcus), S. intermedius, S. constellatus, S. anginosus, S. pneumoniae ATCC 49619, and Streptococcus salivarius ATCC 13419 Escherichia coli American type culture collection (ATCC) 25922, Haemophilus influenzae ATCC 49766, H. influenzae ATCC 49247, Haemophilus parainfluenzae ATCC 7901, K. pneumoniae ATCC 700603, Moraxella catarrhalis ATCC 25238, Staphylococcus aureus ATCC 29247, Neisseria gonorrhoeae ATCC 49226, Neisseria lactamica ATCC 23970, Pseudomonas aeruginosa ATCC 27853, Enterococcus faecalis ATCC 29212.

\section{GAS PCR retrospective clinical specimen study}

We used specimens for the PCR evaluation that had been previously collected as part of a study comparing flocked swabs to conventional swabs for detection of GAS by culture [3]. Physicians obtained throat specimens from patients seen in the Children's Hospital of Eastern Ontario (CHEO) Emergency Department, using dual swabs with flocked and conventional swab attached to the same base. The initial study was conducted from September to December 2007. Research Ethics Board approval was obtained and consent was required from each participant.

After samples were collected, the flocked swab was removed from the dual swab applicator base and placed into a transport tube containing $1 \mathrm{ml}$ Liquid Stuarts transport media. The conventional swab was placed in a traditional throat swab transport tube. Both tubes were then sent to the on-site bacteriology laboratory.

The conventional swab was used to directly streak a $5 \%$ blood agar (BA) plate. The transport tube containing the flocked swab was briefly vortexed. The flocked swab was then used to directly streak a second BA plate and $100 \mu \mathrm{L}$ of the liquid media was streaked onto a third BA plate. Plates were incubated anaerobically for 24 hours prior to examination. Group A streptococci were identified by hemolysis, colony size, latex agglutination and bacitracin susceptibility. Five-hundred microliters of the liquid transport media was saved frozen at $-80^{\circ} \mathrm{C}$ for future DNA extraction.

\section{GAS PCR study specimens}

Three-hundred forty-four dual swabs were collected in the swab comparison study. Six swabs were excluded from analysis since they were improperly collected. Of the 338 liquid transport media specimens saved, 32 were consumed in preliminary comparisons of a variety of nucleic acid extraction methods. Three-hundred and six (90.5\%) of the properly collected fluid specimens were thus available for testing with the GAS PCR assay.

\section{DNA extraction}

The saved volume of flocked swab transport medium was thawed and then centrifuged for 3 minutes at $16000 \times g$. The supernatant was removed and $40 \mu \mathrm{L}$ of PrepMan Ultra reagent (Applied Biosystems, Foster City, CA) was added to the pellet and vortexed for 30 seconds. This was

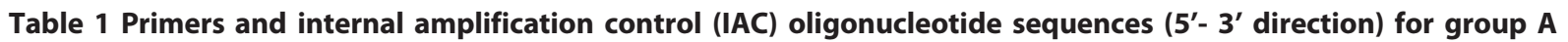
streptococcus (GAS) dnase B assay

\begin{tabular}{ll}
\hline dnaseB forward primer & TGA TTC CAA GAG CTG TCG TG \\
dnaseB reverse primer & TGG TGT AGC CAT TAG CTG TGT T \\
IAC & TGATTCCAAGAGCTGTCGTGatcaatataacaaacacttgcatatatatact \\
& tacgaaactaataactaaataatcaatataaatACACAGCTAATGGCTACACCA
\end{tabular}


then heated at $100^{\circ} \mathrm{C}$ for 10 minutes, and then centrifuged again for 3 minutes at $16000 \times g$. The supernatant was transferred to a new tube and saved at $-80^{\circ} \mathrm{C}$ until testing.

\section{Repeatability and reproducibility}

To assess repeatability, four PCR and culture positive and two negative clinical samples were run in triplicate twice in one day by the same operator using the same lot of master mix [7]. We used two specimens from which 1-10 CFU of GAS were grown in culture as "weak positives" to challenge the assay. To assess reproducibility, the same samples were then tested in triplicate one week later by a different technologist using a different lot of master mix [7].

\section{Main outcome measure and statistical analysis}

The main outcome measures of the study were the performance characteristics (sensitivity and specificity, positive and negative predictive values) of a) the PCR assay and b) the conventional swab culture in comparison to the reference standard results. For statistical analysis, we used as the reference standard a positive culture for GAS from either or both of the two BA plates inoculated from the flocked swab specimen (with the transport liquid or directly with the flocked swab). Confidence intervals for performance characteristics were computed using the Wilson score method [8]. The differences between sensitivities were evaluated with the McNemar's test.

\section{Results}

GAS PCR retrospective clinical specimen study (Table 2)

The sensitivity of the GAS PCR assay as compared to the reference standard was $95 / 99$ (96.0\%, 95\% CI 90.1\% to $98.4 \%)$ with a specificity of $204 / 207$ (98.6\%, 95\% CI $95.8 \%$ to $99.5 \%$ ). The positive predictive value (PPV) was $95 / 98$ (96.9\%, 95\% CI 91.4\% to $99.0 \%$ ) and the negative predictive value $(\mathrm{NPV}) 204 / 208=(98.1 \%, 95 \%$ CI $95.2 \%$ to $99.2 \%)$. Regarding the four PCR-negative reference assay-positive specimens, cultures of the flocked swab liquid media, from which the DNA was extracted for PCR, grew GAS in very

Table 2 Group A streptococcus (GAS) dnaseB PCR and conventional swab culture results compared to the reference standard

\begin{tabular}{lccc}
\hline & \multicolumn{3}{c}{ Flocked swab cultures* } \\
\hline \multirow{2}{*}{ Group A streptococcus dnaseB PCR assay } & + & 95 & - \\
& - & 4 & 3 \\
\hline Conventional swab culture & + & 95 & 0 \\
& - & 4 & 207 \\
\hline
\end{tabular}

*positive GAS culture on $\geq 1$ of the 2 flocked swab blood agar plate cultures light quantities in 3 specimens and was GAS culture-negative from the fourth specimen.

For the conventional swab cultures, sensitivity was also 95/99 (96.0\%, 95\% CI 90.1\% to $98.4 \%)$, with a specificity of $207 / 207$ (100\%, 95\% CI $98.2 \%$ to $100 \%$ ), PPV of $95 / 95$ (100\%, 95\% CI $96.1 \%$ to $100 \%)$ and NPV of $207 / 211$ (98.1\%, 95\% CI $95.2 \%$ to $99.3 \%)$

The mean $T_{\mathrm{m}}$ for the dnaseB peaks was $79.76^{\circ} \mathrm{C}(\mathrm{SD}=$ $\left.0.35^{\circ} \mathrm{C}\right)$. The mean $T_{\mathrm{m}}$ for the IAC peaks was $76.89^{\circ} \mathrm{C}$ $\left(\mathrm{SD}=0.36^{\circ} \mathrm{C}\right)$. Figure 1 illustrates examples of the derivative melt curves for one GAS PCR-positive and two GAS PCR-negative throat swab specimens.

\section{Indeterminate results}

Melting peak graphs for ten specimens of 306 (3.3\%, 95\% CI $1.8 \%$ to $5.9 \%$ ) were judged to be indeterminate and required repeat PCR testing. This group of ten included two specimens with neither IAC nor dnaseB peaks seen on the initial PCR run, and eight specimen results that showed peaks with heights between 5-15 units within the melting temperature range of the dnaseB amplicon. On repeat testing of these 10 specimens, all 10 gave results which could be readily interpreted. (Eight were found to be GAS PCR-negative and two were GAS PCR-positive).

Of note, since a competitive internal control design was used, the presence of either the IAC amplicon or the dnaseB amplicon indicated no PCR inhibition had occurred. Among the dnaseB- positive specimens, both dnase $B$ and IAC peaks were seen in 36/98 (36.7\%) and the dnaseB peak alone in $62 / 98$ (63.3\%).

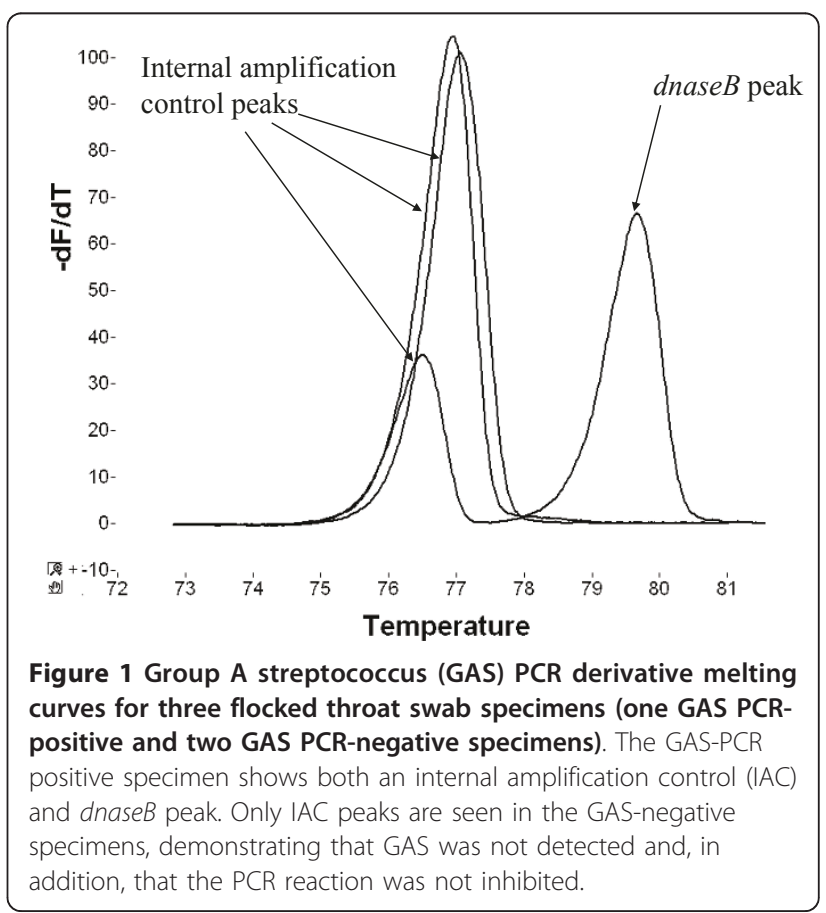




\section{Specificity panel and repeatability and reproducibility}

The specificity panel study showed no amplicons that could lead to false positive GAS results. The 18 qualitative (positive or negative) PCR results were identical for the tests performed twice on the same day to assess repeatability as well as for those obtained when testing was performed one week later by a different operator with a different master mix lot to assess reproducibility.

\section{Discussion}

The rapid internally-controlled GAS PCR assay described performed as well as the currently accepted standard method of conventional swab culture for GAS detection. PCR assay sensitivity of $96 \%$ was also similar to that seen in two prior prospective studies comparing PCR to culture GAS detection from throats swabs. In a study using dot blot and Southern Blot detection of PCR products from throat swabs, GAS detection sensitivity was also 96\% [1], while the sensitivity of a fluorescent probe-based PCR detection method was $93 \%(82-98 \% \mathrm{CI})$ with a specificity of $98 \%$ (96-99\% CI) [2].

Although a small number of specimens were reference assay- positive/PCR-negative, culture results from these specimens indicated that only specimens containing very low quantities of GAS may possibly be missed by PCR assay. As well, colonization of the pharynx with GAS is relatively common in pediatric patients, and recovery of GAS in low quantities by culture may not be clinically significant, as GAS may be a colonizer rather than the cause of pharyngitis in some cases. The high specificity of the GAS PCR assay ensures laboratories will only rarely encounter the dilemma of PCR-positive, culture-negative specimens.

The GAS PCR assay may be useful for clinical laboratories. It is relatively rapid, since it can be performed in approximately one hour, including the DNA extraction procedure, and as a closed-tube method, has a low risk of environmental cross-contamination. However, the assay is less suitable for medical office settings as compared to rapid antigen detection tests since more manual steps are required and since the turnaround time may be longer. The per reaction cost for the GAS LCGreen assay is low, at approximately $\$ 2.40$ US, including DNA extraction and PCR reagents and consumables, but not including swab costs and personnel time.

The GAS PCR assay also demonstrates for the first time the clinical usefulness of flocked swabs in liquid transport media for bacterial molecular assays. Flocked swabs are created by attaching individual short fibers to an applicator, rather than winding long fibers around the applicator, as with conventional swabs. Due to this design, flocked swabs release a larger volume of specimen into the liquid transport media than conventional wound fiber swabs.
This liquid media can then be used for nucleic acid extraction for molecular assays. Molecular testing from flocked swab clinical samples has previously been reported for detection of viral agents [9], but to our knowledge, this is the first report to demonstrate the successful use of PCR from flocked swab specimens for bacterial identification using true clinical specimens. (A study using serial dilutions of bacterial reference strains has shown improved sensitivity for nucleic acid amplification assays using flocked swabs [10].)

This assay also provides another example of the usefulness of LCGreen dye for amplicon detection and melting analysis. This dye has been used successfully for applications such as duplex and multiplex PCR where older SYBR Green dyes may be sub-optimal [4,5]. The SYBR Green dyes have been described, to have a tendency to bind preferentially to certain amplicons or due to inhibition of PCR by the dye itself [11]. In contrast, the LCGreen dye has been used successfully to detect and differentiated amplicons in duplex and multiplex PCR assays for the identification of infection agents, such as Aspergillus spp. and Mycobacterium spp., and for detection of antibiotic resistance genes $[4,12,13]$. LCGreen assay could be adapted successfully to any of several real-time thermocyclers compatible with this dye [14], so the GAS PCR we describe should be readily transferable to these instruments.

There are several limitations to our study. First, not all specimens collected in the original flocked swab study were available for testing with the PCR assay. However, the proportion positive for GAS by culture in the original study and in this study were similar, suggesting that this factor would not introduced bias into the PCR study. Secondly, samples were tested retrospectively after being saved frozen rather than being tested immediately after collection. We cannot exclude the possibility that freezing and thawing may have affected study results in some way.

A third limitation is that not all samples positive by the reference standard of positive flocked swab cultures were detected. The PCR sensitivity was, however, equal to that of a wound fiber conventional swab culture, which is currently the standard of practice in clinical microbiology laboratories.

\section{Conclusion}

The GAS PCR assay appears to be an accurate and rapid molecular assay for GAS detection in children and adolescents with pharyngitis. Since the GAS PCR assay, including DNA extraction, can be performed in approximately 1 hour, prospective studies of this assay are warranted to evaluate the clinical impact of the assay on the management of patients with pharyngitis. 


\section{Acknowledgements}

None

\section{Author details}

'Department of Laboratory Medicine, Children's Hospital of Eastern Ontario, University of Ottawa, Ottawa, ON, Canada. ${ }^{2}$ Department of Pediatrics, University of Botswana, Gaborone, Botswana. ${ }^{3}$ Research Institute, Children's Hospital of Eastern Ontario, University of Ottawa, Ottawa, ON, Canada.

\section{Authors' contributions}

RS drafted the primary manuscript. RS and DG designed the PCR assay. NB performed statistical analyses. DG, RT, FC contributed to study design and data collection and analysis. DR and IM participated in the performance of the PCR assay and data analysis. All authors contributed to the preparation of the manuscript. All authors read and approved the final manuscript.

\section{Competing interests}

The authors declare that they have no competing interests.

Received: 16 May 2011 Accepted: 2 September 2011 Published: 2 September 2011

\section{References}

1. Kaltwasser G, Diego J, Welby-Sellenriek PL, Ferrett R, Caparon M, Storch GA: Polymerase chain reaction for Streptococcus pyogenes used to evaluate an optical immunoassay for the detection of group A streptococci in children with pharyngitis. Pediatr Infect Dis J 1997, 16:748-753.

2. Uhl JR, Adamson SC, Vetter EA, Schleck CD, Harmsen WS, Iverson LK, et al: Comparison of LightCycler PCR, rapid antigen immunoassay, and culture for detection of group A streptococci from throat swabs. J Clin Microbiol 2003, 41:242-249.

3. Goldfarb DM, Slinger R, Tam RK, Barrowman N, Chan F: Assessment of flocked swabs for use in identification of streptococcal pharyngitis. J Clin Microbiol 2009, 47:3029-3030.

4. Erali M, Pounder Jl, Woods GL, Petti CA, Wittwer CT: Multiplex single-color PCR with amplicon melting analysis for identification of Aspergillus species. Clin Chem 2006, 52:1443-1445.

5. Podbielski A, Zarges I, Flosdorff A, Weber-Heynemann J: Molecular characterization of a major serotype M49 group A streptococcal DNase gene (sdaD). Infect Immun 1996, 64:5349-5356.

6. Steve R, Skaletsky HJ: Primer3 on the WWW for general users and for biologist programmers. In Bioinformatics Methods and Protocols: Methods in Molecular Biology. Edited by: Krawetz S, Misener S. Totowa: Humana Press; 2000:365-386

7. Clinical and Laboratory Standards Institute: Verification and validation of multiplex nucleic acid assays; approved guideline MM17-A. Wayne, PA: 2008.

8. Newcombe RG: Two-sided confidence intervals for the single proportion: comparison of seven methods. Statistics in Medicine 1998, 17:857-872.

9. Abu-Diab A, Azzeh M, Ghneim R, Ghneim R, Zoughbi M, Turkuman S, et al: Comparison between pernasal flocked swabs and nasopharyngeal aspirates for detection of common respiratory viruses in samples from children. J Clin Microbiol 2008, 46:2414-2417.

10. Chernesky M, Castriciano S, Jang D, Smieja M: Use of flocked swabs and a universal transport medium to enhance molecular detection of Chlamydia trachomatis and Neisseria gonorrhoeae. J Clin Microbiol 2006, 44:1084-1086.

11. Giglio $S$, Monis PT, Saint CP: Demonstration of preferential binding of SYBR Green I to specific DNA fragments in real-time multiplex PCR. Nucleic Acids Res 2003, 31:e136.

12. Odell ID, Cloud JL, Seipp M, Wittwer CT: Rapid species identification within the Mycobacterium chelonae-abscessus group by high-resolution melting analysis of hsp65 PCR products. Am J Clin Pathol 2005, 123:96-101.

13. Slinger R, Desjardins M, Moldovan I, . Harvey S-B, Chan F: A Rapid HighResolution Melting Multiplex PCR Assay to Detect Macrolide Resistance Determinants in Group A Streptococcus. Int I Antimicrob Agents, in press .

14. Herrmann MG, Durtschi JD, Wittwer CT, Voelkerding KV: Expanded instrument comparison of amplicon DNA melting analysis for mutation scanning and genotyping. Clin Chem 2007, 53:1544-1548. doi:10.1186/1476-0711-10-33

Cite this article as: Slinger et al:: Rapid PCR detection of group a streptococcus from flocked throat swabs: A retrospective clinical study. Annals of Clinical Microbiology and Antimicrobials 2011 10:33.

\section{Submit your next manuscript to BioMed Central and take full advantage of:}

- Convenient online submission

- Thorough peer review

- No space constraints or color figure charges

- Immediate publication on acceptance

- Inclusion in PubMed, CAS, Scopus and Google Scholar

- Research which is freely available for redistribution

Submit your manuscript at www.biomedcentral.com/submit
Biomed Central 